\title{
Electrical Machine Rotor Shielding for Low Cost Electrical Drive
}

\author{
M.M.J. Al-Ani, G. Vakil and C. Gerada \\ Power Electronics, Machines and Control (PEMC) Group \\ University of Nottingham \\ Nottingham, UK
}

\begin{abstract}
Electrical machine rotor shielding has been proposed for high-speed electrical machines, i.e. $\geq 50 \mathrm{krpm}$, where a smooth current waveform becomes difficult and costly to generate due to the required high switching frequency. The rotor shielding is used to suppress the unsynchronized low order high amplitude current harmonics and consequently reduces the induced eddy-current losses in rotor. For moderate speed machines, 10-40krpm, generally suited for automotive applications, a smooth current waveform is possible to generate, however, fast switching devices are required that increases the overall drive cost. In the paper, a feasibility study of low cost electrical drive is presented. The electrical drive consists of low cost, low switching frequency modules to generate a pulse width modulation (PWM) current waveform with a few switching pulses, and a rotor with electromagnetic shield to reduce the losses to an acceptable level. The feasibility study includes two permanent magnet machines (PMMs) with different rotors. Multi-physics results are obtained and compared to illustrate the feasibility of the proposed drive.
\end{abstract}

Keywords-Shielding, harmonics, low cost, surface-mounted permant magnet machine, SPM, soild rotor, low siwtching frequancy

\section{INTRODUCTION}

For high-speed machines, the influence of the current waveform shape on the electrical machine has been addressed in [1] and [2]. The work concluded that, high switching frequency generated current waveform can move the losses from the rotor to the inverter at the expense of decreasing the overall efficiency of the drive. Whereas low frequency generated current waveform such as pulse amplitude modulation (PAM) can increase the drive efficiency by decreasing the inverter losses, despite the need for extra DC to DC converter, but potentially would increases rotor losses due to increased harmonics.

Copper shielding for high-speed rotors was firstly proposed by van der Veen in 1997 [3]. The copper shield was proposed alongside rectifier load to reduce the rotor eddy-current losses. The work conduced that both, winding sub-division and copper shielding, can reduce the rotor loss to an acceptable level, i.e. $0.1-0.2 \%$ of the rated power. Further work on this topic was reported in [4-5], where copper shielding and magnet segmentation have been investigated for rotor loss reduction, and to validate the concept a locked rotor measurement together with measuring current and voltage waveforms have been performed. In [6], copper shield for high-speed surface-mounted permanent magnet (SPM) machine was selected based on skin depth of the unsynchronized harmonics in the current waveform. Additionally, the work presents a steady-state thermal analysis of the rotor with copper shield. MMF harmonic analysis of different SPM machine combinations has been conducted to select the thickness of the copper shield and have been reported in [7-8]. Similar work has been conducted on solid rotor machines reported in [9]. Copper shield for BLDC generator was proposed by [10], an E-core equivalent model was tested for validation. The torque production of the SPM machine with copper shield was investigated in [11] emphasizing on the torque produced by the copper shield. Finally, a preliminary mechanical analysis as well as feasibility study of the copper shield taking in consideration the copper shield location, current harmonic, sleeve material and rotor speed was reported in [12].

From the literature review, the following can be concluded:

- Copper shield is preferred for machines fed with highly distorted current waveform generated by low switching modules,

- Copper shield was proposed for high-speed machines, their possibility for moderate speed machines was not addressed,

- The possibility of using copper shield for moderate speed machine with low switching modules that can reduce the drive cost and maintain the same drive efficiency has not been explored,

- Thorough mechanical and thermal analysis of the electrical machine rotor with copper shield has not been conducted,

- Copper shield manufacturability has not been addressed,

This paper presents a feasibility study for a low cost electrical machine drive, where a low switching frequency converter can be used to reduce the converter cost and losses at the expense of a highly distorted current waveform. The effect of highly distorted current waveform can be remedied by copper shielding the rotor, in order to reduce the eddy-current losses to an acceptable level. To explore the possibility of such drive a feasibility study has been conducted. Two permanent magnet machines (PMMs) with different rotor topologies has been investigated. The electromagnetic losses of both rotors with different copper shield thicknesses and location has been studied. A mechanical analysis to investigate the mechanical stability of the rotors with and without copper shield has been conducted. Finally, steady-state thermal analysis of both rotors with and without with copper shield has been carried on to compare the maximum rotor temperature and the location of the hot spots. 


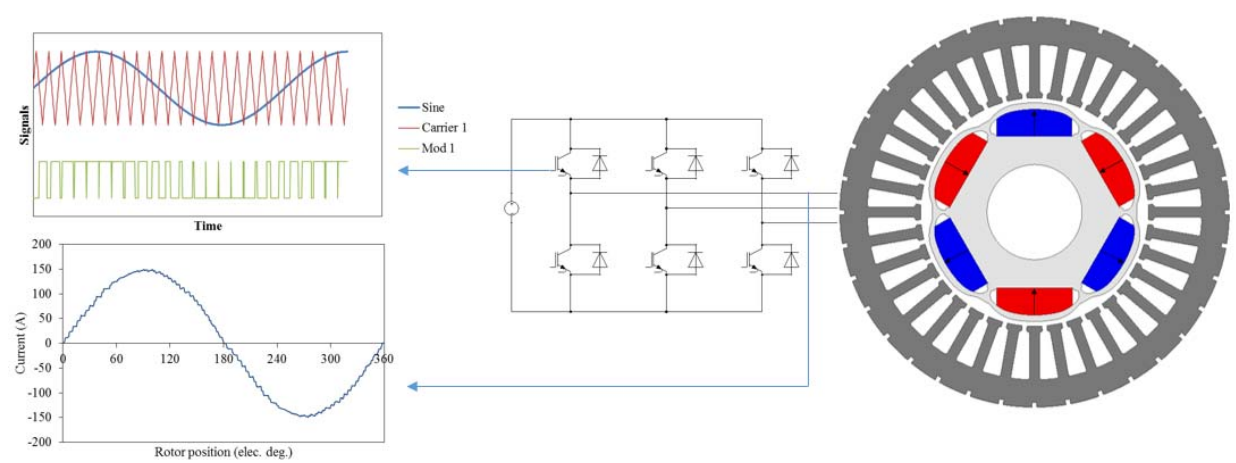

(a) Convectional drive, high switching frequency devices and conventional electrical machine

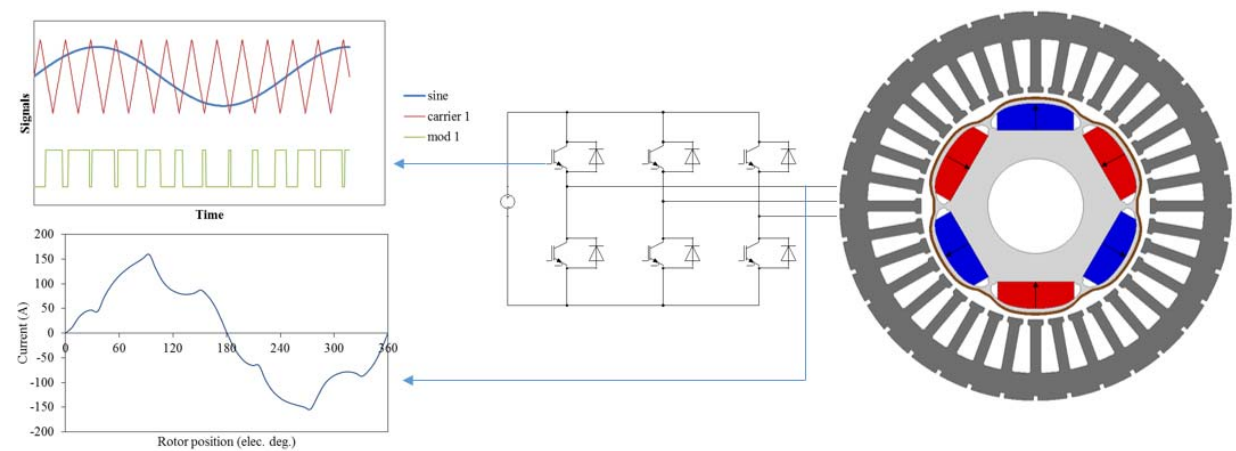

(b) Low cost drive, low switching frequency devices and electrical machine with copper shielded rotor

Fig. 1. Conventional and low cost drives layout highlighting the diffrent converter switching and electrical machine stracture

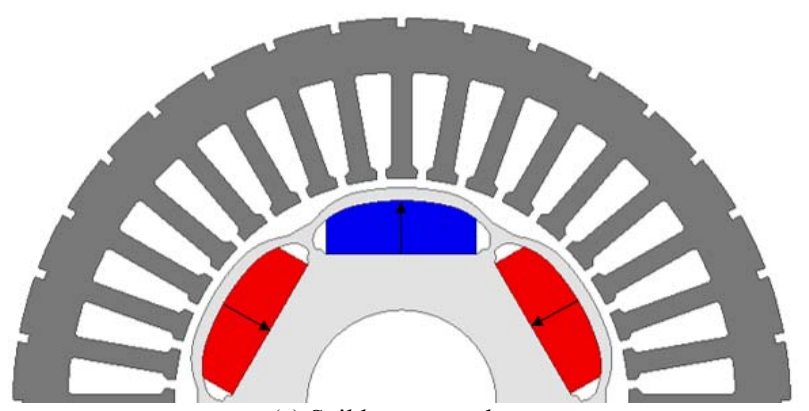

(a) Soild rotor topology

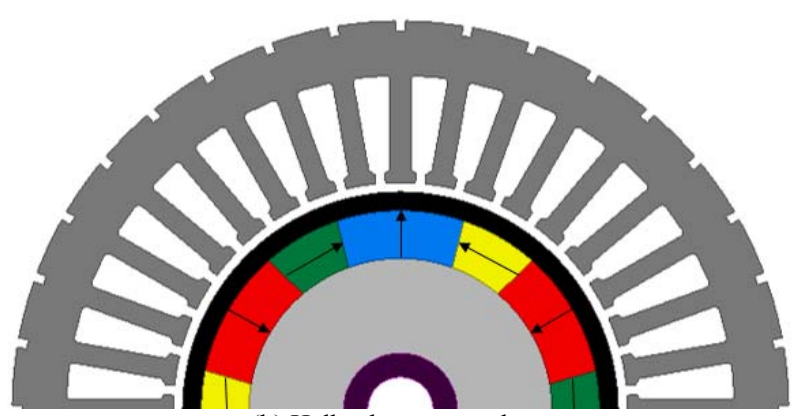

(b) Halbach rotor topology

Fig. 2. Permanent magnet machines with different rotor topologies

Fig. 1 presents the layout of the conventional and low cost drives highlighting the different switching patterns used for conventional drive and low cost drive. Also, for the low cost drive a shielded rotor in considered for the PPM, in order to achieve a comparable performance to the conventional SPM. To illustrate the effect of the copper shield on the electrical machine, two PM machine topologies, solid rotor Fig. 2 (a) and Halbach rotor Fig. 2 (b), are used in this investigation. Solid rotor topology consists of solid electrical steel structure with interior permanent magnets (IPMs), whereas the Halbach topology consists of traditional SPM rotor structure with PMs in Halbach array and retaining sleeve to ensure the mechanical safety of the magnets.

\section{ELECTROMAGNETIC LOSSES}

Using 2D-FEA, two different current waveforms are used to evaluate the effectiveness of copper shield for two different PM rotor topologies. The first current waveform, shown in Fig. 1 (a), is generated by high switching inverter. This current waveform named fast switching waveform (FSW). The second waveform is generated by low switching inverter, low switching waveform (LSW). The copper shield is placed around the rotor in the solid rotor IPM topology, whereas the in Halbach rotor SPM topology two copper shield locations where investigated, around the rotor (outer) and between the sleeve and magnets (inner).

Fig. 3 presents the total rotor losses at different copper shield thickness, $0 \mathrm{~mm}$ thickness presents the normal machine without the copper shield, and a rotor speed of $20 \mathrm{krpm}$ is used. By observing the changes in the rotor loss with copper shield thickness in the solid rotor, it can be seen that although the FSW has slightly lower total rotor loss when the copper shield is not used, the FSW exhibits significantly higher loss with copper shield in comparison with the LSW. This is since the FSW has the high order, low amplitude harmonics which penetrate through the surface of the rotor. As a result, when high conductive copper shield placed around the rotor, these 
harmonics increase the total loss. However, with LSW, the low order, high amplitude harmonics penetrate deep through the rotor and the magnets and therefore, the copper shield is more effective in suppressing these harmonics and reducing the total rotor losses. Fig. 4 (a) shows the induced eddy current in the solid rotor due to the harmonics.

On the other hand, the Halbach machine with inner shield exhibits a good reduction in the losses due to the carbon fiber sleeve situated between the airgap and the shield resulting in seeing the harmonics influence on the magnets, as shown in Fig.4 (c). However, with outer shield, Fig. 3 (c), similar effect to that of the solid rotor is found. The low order harmonics generated by the FSW waveform produce losses in the copper leading to an increase the total loss. Fig. 4 (d) and (e) presents the eddy current induced in the rotor due to the harmonics.

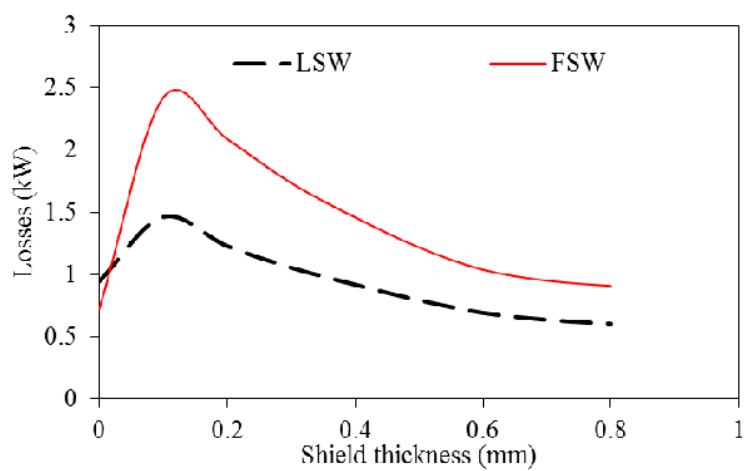

(a) Solid rotor machine

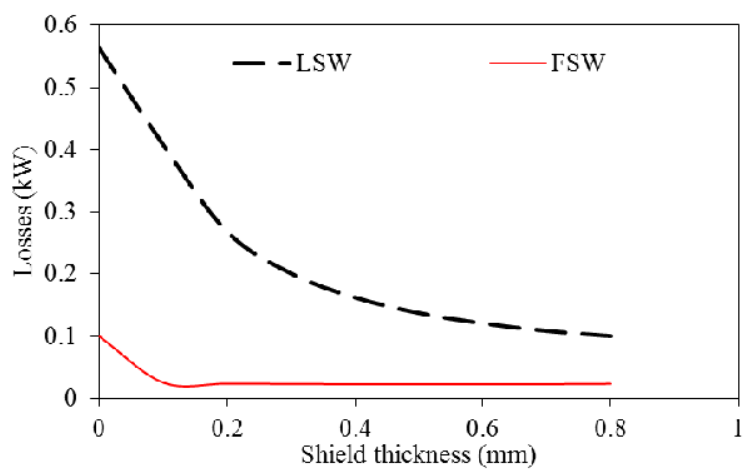

(b) Halbach machine with inner shield

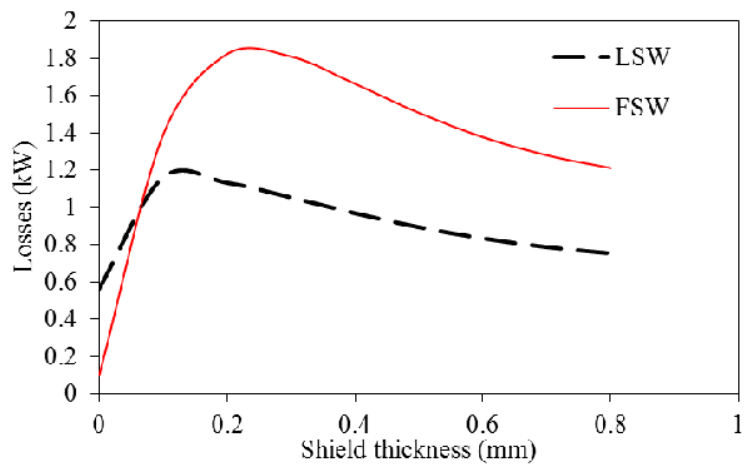

(c) Halbach machine with outer shield

Fig. 3. Rotor losses versues copper shield thickness in the soild and halbach (inner and outer) machines at $20 \mathrm{krpm}$ rotor speed.
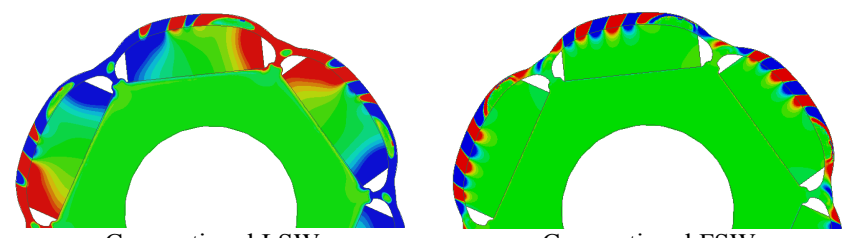

Conventional FSW

(a) Solid rotor machine without shield

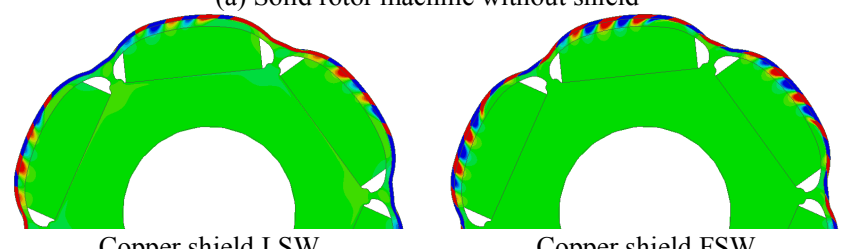

Copper shield LSW

Copper shield FSW

(b) Solid rotor machine with shield
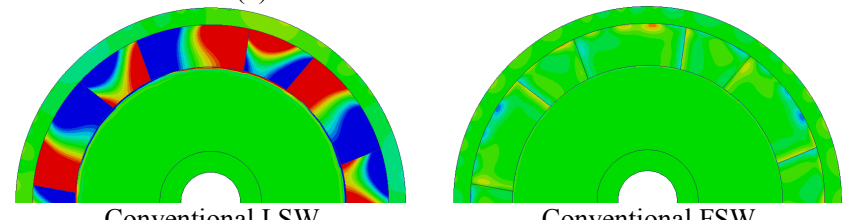

Conventional FSW

(c) Halbach machine without shield

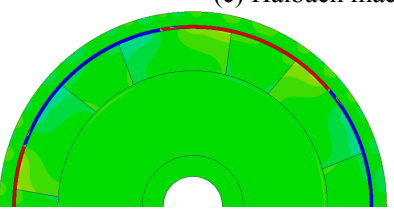

Copper shield LSW (d) Halbach machine with inner shield

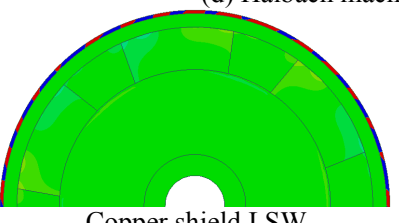

Copper shield LSW

(e) Halbach machine with outer shield
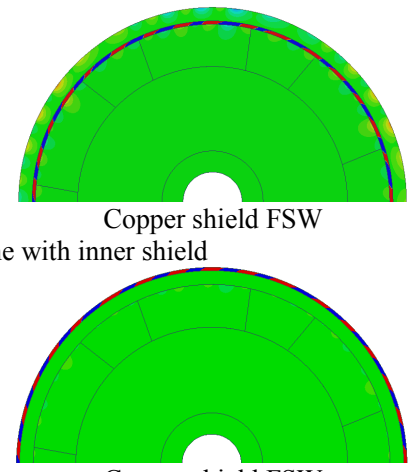

Copper shield FSW

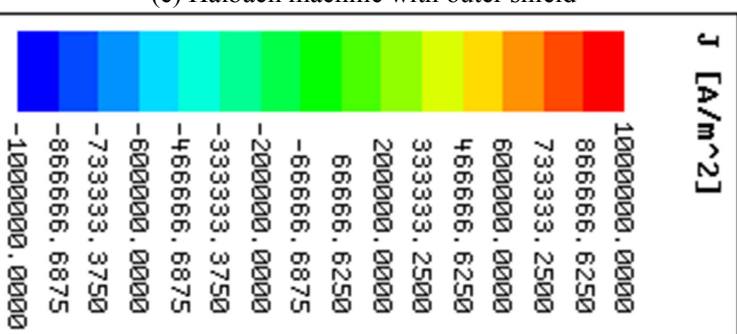

Scale

Fig. 4. Eddy current indced in the rotor due to unsycronused harmonics in the soild and halbach rotors with and without copper shield.

For the solid rotor, when LSW is used, i.e. low cost drive, a copper shield with a thickness of $0.4 \mathrm{~mm}$ can bring the total rotor losses to the same level, i.e. $750 \mathrm{~W}$, of a conventional rotor (without shield) supplied by a smoother current waveform, i.e. FSW waveform. However, for the Halbach machine with inner shield, a shield thickness of $0.8 \mathrm{~mm}$ is needed to bring the losses to the same level, i.e. $100 \mathrm{~W}$, of the conventional rotor (without shield) supplied by a smoother current waveform, FSW. Finally, with outer shield in the Halbach rotor, the thickness of the shield need to be significantly large to bring the losses to an acceptable level, i.e. same level as the conventional rotor with FSW waveform. 


\section{STRACTURAL ANALYSIS}

The mechanical strength of the copper is relatively low in comparison with the other materials used in the rotors. In addition, the copper shield thickness reduces either the sleeve in the Halbach rotor or the rotor outer frame in the solid rotor. Therefore, mechanical analysis is needed to ensure the mechanical safety of the rotors. 2D-FEA structural analysis is conducted on the two rotors with and without copper shield. The mechanical properties of the rotor components are listed in Table II. The conditions for the analysis of the solid rotor are 1) rotational speed of $32 \mathrm{krpm}, 2$ ) fixed support at the inner radius, and 3) frictional contact between the magnet and core with friction coefficient of 0.3 and interference fit of $0.005 \mathrm{~mm}$. The analysis of Halbach rotor consist of the following conditions 1) rotational speed of $32 \mathrm{krpm}, 2$ ) interference fit between the sleeve and magnet/inner copper shield of $0.05 \mathrm{~mm}$, and 3) bonded contact between the other rotor components. It is worth noting that a copper shield of $0.8 \mathrm{~mm}$ was used since it is the largest investigated thickness which results in the largest reduction of the rotor structure integrity.

TABLE I

MEChANiCAL PRoperties of THE ROTOR COMPONENTS MATERIALS

\begin{tabular}{|c|c|c|c|c|}
\hline & $\begin{array}{c}\text { Young's } \\
\text { modulus } \\
(\mathrm{GPA})\end{array}$ & $\begin{array}{c}\text { Poisson's } \\
\text { ratio }\end{array}$ & $\begin{array}{c}\text { Mass } \\
\text { density } \\
\left(\mathrm{Kg} / \mathrm{m}^{3}\right)\end{array}$ & $\begin{array}{c}\text { Yield } \\
\text { strength } \\
(\mathrm{MPa})\end{array}$ \\
\hline SS146 & 137 & 0.3 & 7650 & 1500 \\
\hline Carbon fiber & 250 & 0.3 & 1600 & 2000 \\
\hline SmCo & 100 & 0.27 & 8300 & 40 \\
\hline 304SS & 200 & 0.29 & 8000 & 215 \\
\hline Copper & 128 & 0.36 & 8900 & 100 \\
\hline
\end{tabular}

In the conventional solid rotor machine without copper shield, the maximum equivalent stress (von-Mises) in the core and magnets should not exceed the yield of their respective materials. On the other hand, in the Halbach rotor the modes of mechanical safety that need to be ensured are 1) the circumferential stress in magnet inner radius should not exceeds the compressive strength of the magnet when the rotor in standstill, 2) the maximum equivalent stress (von-Mises) in the sleeve inner radius should not exceeds the yield of the sleeve material at the maximum operating speed, and 3) the circumferential stress in magnet inner radius should not exceeds the yield strength of the magnet.

When inner copper shield is used in the Halbach rotor, the copper shield can withstand much larger yield circumferential stresses due to increased centripetal loading than the magnet, as a result, the stiffer sleeve will carry the stresses due to interference. However, when outer copper shield is used in the solid and Halbach rotors, the modes of mechanical failure that need to be taken in consideration are: 1) the equivalent stress (von-Mises) in the copper should not exceeds the yield stress of the copper, if exceeded the subsequent plastic stain should not exceeds the strain at rupture and 2) the radial stress of the contact between the copper and sleeve in the Halbach rotor or contact between the copper and core material in the solid rotor should not exceeds the cohesive strength of the contact.

Fig. 5 presents the mechanical equivalent stress (von-Mises) in the solid and Halbach rotors with and without copper shield.
It can be seen that when the copper shield is added, the equivalent stress in the solid rotor frame and Halbach sleeve have increased slightly and therefore, adding the copper shield have a negligible effect on the mechanical integrity of the rotors. However, with outer copper shield in both rotors the equivalent stress in the copper has exceeded the yield strength of the copper and therefore, the subsequent maximum plastic strain needs to be examined. The maximum equivalent plastic strain in the copper for both solid and Halbach machines are 0.14 and 0.11 , respectively. These values are lower than the copper strain at rupture which is 0.33 . Therefore, the first failure mode is examined and the rotor will operate safely at $32 \mathrm{krpm}$. On the other hand, the radial stress in the outer copper shield in solid and Halbach rotors are $3.8 \mathrm{MPa}$ and $3.2 \mathrm{MPa}$, respectively. This failure condition can only be verified if the cohesive strengths between the copper and - the core and the sleeve material are known. This needs experimental measurement to be obtain which would be an interesting future work.

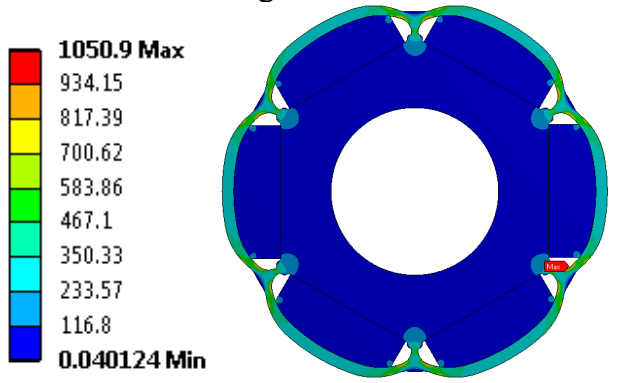

(a) Solid rotor without copper shield

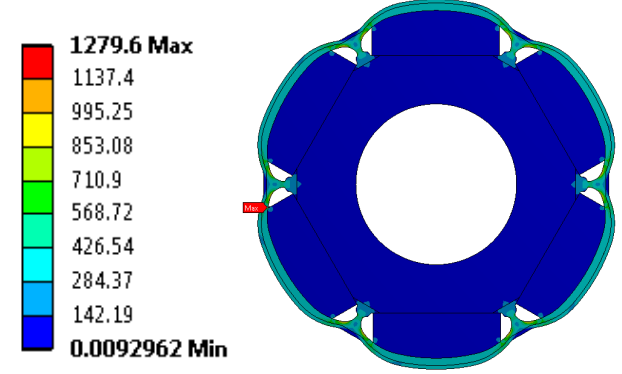

(b) Solid rotor with copper shield

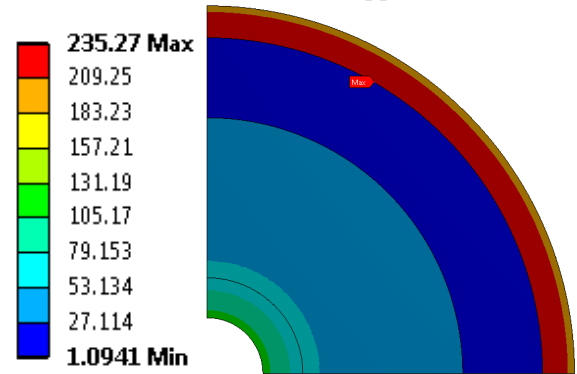

(c) Halbach rotor without shield

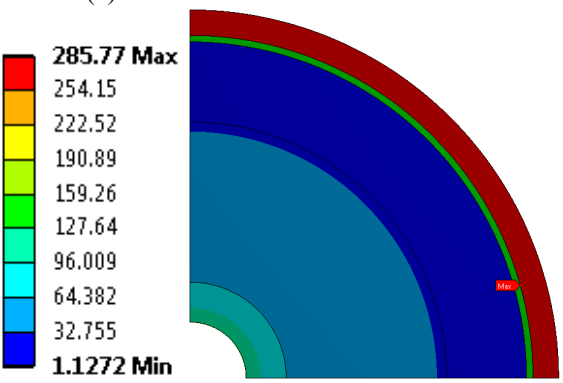

(d) Halbach rotor with inner shield 


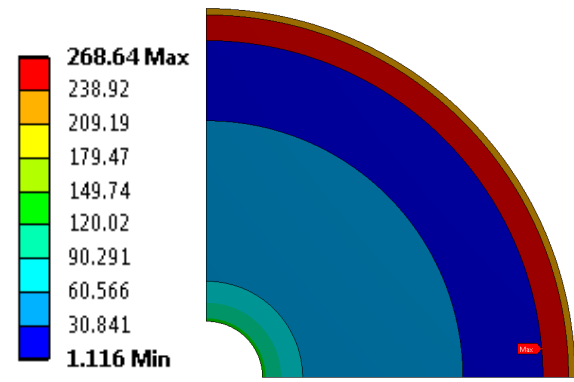

(e) Halbach rotor with outer shield

Fig. 5. Mechancial equivlent (von-Mises) stress (MPa) in the soild and halbach rotors with and without copper shield.

\section{THERMAL ANALYSIS}

Thermal evaluation of the machines with copper shield has been conducted using steady-state 2D-FEA. The thermal properties of the different materials are shown in Table II. The equivalent winding properties and the airgap thermal convection has been calculated using the methods reported in [13] and [14], respectively. The analysis conditions are fixed temperature of $60^{\circ} \mathrm{C}$ at the outer cooling channels and the airgap cooling sleeve, whereas a fixed temperature of $100^{\circ} \mathrm{C}$ in the shaft is set to simulate the axial heat dissipation from the shaft assuming the shaft will maintain a temperature of $100^{\circ} \mathrm{C}$. Similar to the mechanical analysis a copper shield of $0.8 \mathrm{~mm}$ is used in this analysis.

TABLE II

MeChaNiCAl PROPERTIES OF THE ROTOR COMPONENTS MATERIALS

\begin{tabular}{|c|c|}
\hline & Thermal conductivity $\left(\mathrm{W} / \mathrm{m}^{\circ} \mathrm{C}\right)$ \\
\hline SS146 & 25 \\
\hline Carbon fiber & 50 \\
\hline SmCo & 9.6 \\
\hline 304SS & 125 \\
\hline Copper & 401 \\
\hline Equivlent winding & 0.5 \\
\hline JNX900 & 25 \\
\hline Air & 0.026 \\
\hline
\end{tabular}

Figs. 6 and 7 present the temperature distribution in the solid and Halbach machine, respectively. It can be seen that when copper shield is used in the solid rotor machine with LSW, the maximum temperature in the rotor reduces to $153^{\circ} \mathrm{C}$ compared to the solid rotor without copper shield and with FSW where the maximum temperature in the rotor is $183^{\circ} \mathrm{C}$. Additionally, the maximum temperature, i.e. hot spot, moves from concentrated above the magnet to around the outer frame of the rotor. On the other hand, using outer copper shield in the Halbach rotor leads to an increase in the maximum temperature and a concentration of the heat near the airgap. Although the total rotor losses reduces when inner copper shield is used, the maximum temperature reducers slightly with FSW and increases by $10^{\circ} \mathrm{C}$ with LSW due to the location of the shield between the magnet and the sleeve.

\section{CONCLUSION}

This paper propose a feasibility study of low cost drive consists of an inverter with low switching frequency modules which generates a highly distorted current waveform and an electrical machine with copper shield to mitigate the unsynchronized current harmonics. The feasibility study included electromagnetic losses in the rotor, mechanical integrity of the rotors with and without the copper shield and thermal comparison of the rotors with and without copper shield. Two different PM machines were investigated, a solid rotor IPM and a conventional SPM machine with Halbach array magnets.

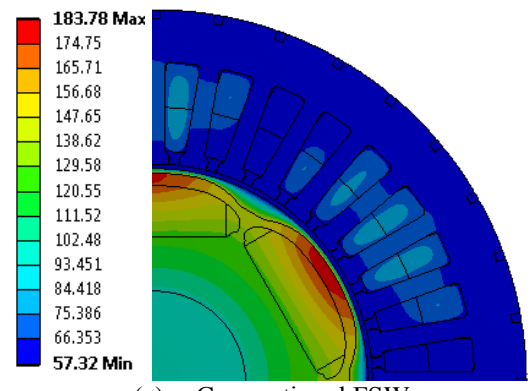

(a) Conventional FSW

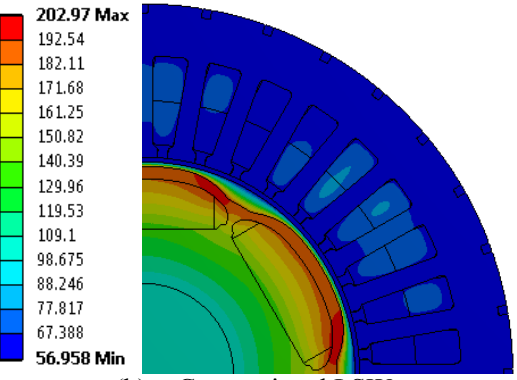

(b) Conventional LSW

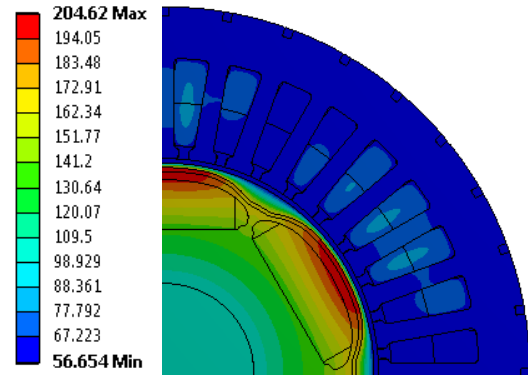

(c) Copper shield FSW

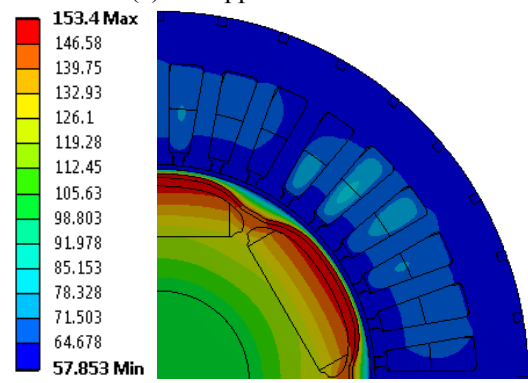

(d) Copper shield LSW

Fig. 6. Temprautre distibution in the soild rotor with and without copper shield.

From the study it can be concluded that, the copper shield in solid rotor machine with highly distorted current waveform can reduces the rotor loss to the same level of a conventional electrical machine fed by a smooth current waveform. In Halbach rotor, inner copper shield, i.e. between sleeve and magnet, can reduce the total rotor losses. Mechanically, both rotors can operate safely at the maximum speed with a small 
degradation of their mechanical integrity when a copper shield is included. Moreover, the copper shield can withstand the forces generated by the high rotation. Finally, thermal analysis shown that in the solid rotor machine the temperature reduces when copper shield is used with distorted current waveform, whereas small increase in the temperature is found in the Halbach rotor with inner shield.

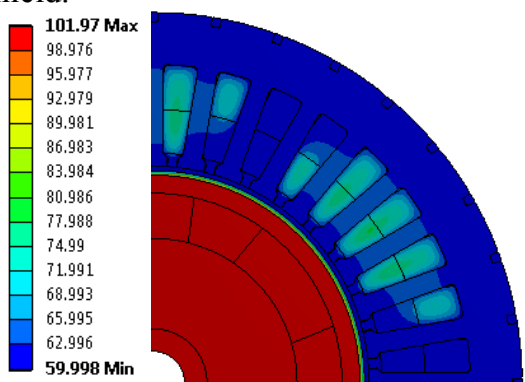

(a) Conventional FSW

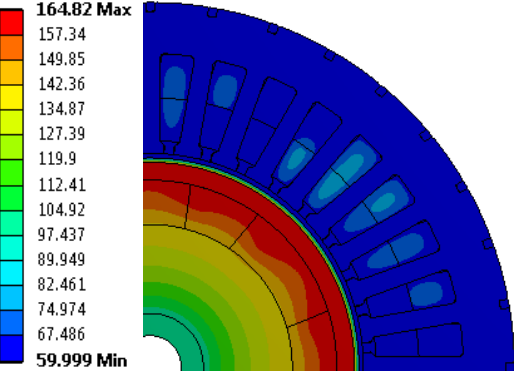

(b) Conventional LSW

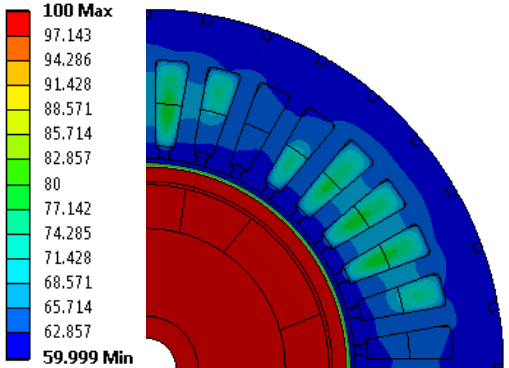

(c) Inner copper shield FSW

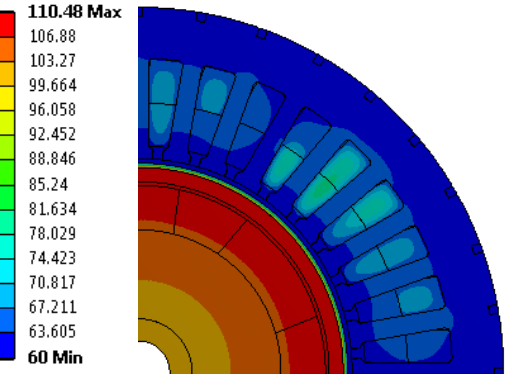

(d) Inner copper shield LSW
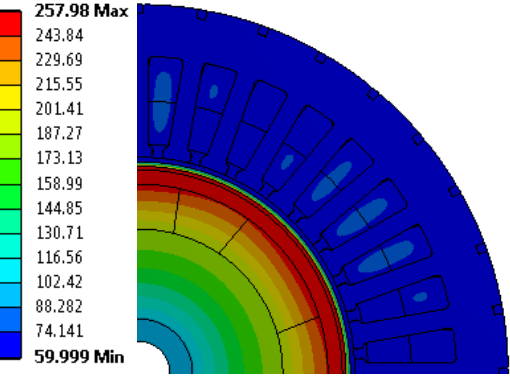

(e) Outer copper shield FSW

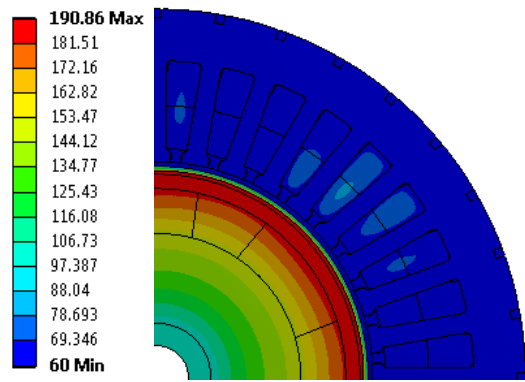

(f) Outer copper shield LSW

Fig. 7. Temprautre distibution in the Halbach rotor with and without copper.

\section{ACKNOWLEDGEMENT}

This work was supported by the Ningbo Science \& Technology Bureau under Grant 2013A31012 and Grant 2014 A35007.

\section{REFERENCES}

[1] L. Schwager, A. Tüysüz, C. Zwyssig and J. W. Kolar, "Modeling and Comparison of Machine and Converter Losses for PWM and PAM in High-Speed Drives," in IEEE Transactions on Industry Applications, vol. 50, no. 2, pp. 995-1006, MarchApril 2014

[2] M. M. J. Al-Ani, J. Carter and M. L. Jupp, "Comparison of electromagnetic performance and power losses of a high-speed machine fed by PWM and PAM inverter strategies," 8th IET International Conference on Power Electronics, Machines and Drives (PEMD 2016), Glasgow, 2016, pp. 1-6.

[3] J. L. F. Van der Veen, L. J. J. Offringa and A. J. A. Vandenput, "Minimising rotor losses in high-speed high-power permanent magnet synchronous generators with rectifier load," in IEE Proceedings - Electric Power Applications, vol. 144, no. 5 , pp. 331-337, Sep 1997.

[4] H. Polinder and M. J. Hoeijmakers, "Modelling a PM machine with shielding cylinder," 1999. Ninth International Conference on Electrical Machines and Drives (Conf. Publ. No. 468), Canterbury, 1999, pp. 16-20.

[5] H. Polinder and M. J. Hoeijmakers, "Effect of a shielding cylinder an the rotor losses in a rectifier-loaded PM machine," Conference Record of the 2000 IEEE Industry Applications Conference. Thirty-Fifth IAS Annual Meeting and World Conference on Industrial Applications of Electrical Energy (Cat. No.00CH37129), Rome, 2000, pp. 163-170 vol.1.

[6] F. Zhou, J. Shen, W. Fei and R. Lin, "Study of Retaining Sleeve and Conductive Shield and Their Influence on Rotor Loss in High-Speed PM BLDC Motors," in IEEE Transactions on Magnetics, vol. 42, no. 10, pp. 3398-3400, Oct. 2006.

[7] M. R. Shah and A. M. EL-Refaie, "Eddy-Current Loss Minimization in Conducting Sleeves of Surface PM Machine Rotors With Fractional-Slot Concentrated Armature Windings by Optimal Axial Segmentation and Copper Cladding," in IEEE Transactions on Industry Applications, vol. 45, no. 2, pp. 720-728, March-april 2009.

[8] M. R. Shah and A. M. EL-Refaie, "Eddy Current Loss Minimization in Conducting Sleeves of High Speed Machine Rotors by Optimal Axial Segmentation and Copper Cladding," 2007 IEEE Industry Applications Annual Meeting, New Orleans, LA, 2007, pp. 544-551.

[9] M. R. Shah and Sang Bin Lee, "Rapid analytical optimization of eddy-current shield thickness for associated loss minimization in electrical Machines," in IEEE Transactions on Industry Applications, vol. 42, no. 3, pp. 642-649, May-June 2006.

[10] N. Burany, D. Herceg, and N. Pekaric-Nad, "Influence of a thin copper shield on a BLDC motor parameters," in Electronics, vol. 16, no. 1, pp. 37-41, June 2012.

[11] B. Hannon, P. Sergeant and L. Dupré, "Study of the Effect of a Shielding Cylinder on the Torque in a Permanent-Magnet Synchronous Machine Considering Two Torque-Producing Mechanisms," in IEEE Transactions on Magnetics, vol. 53, no. 10, pp. 1-8, Oct. 2017.

[12] M. M. J. Al-ani, S. M. Barrans and J. Carter, "Electromagnetic and mechanical analysis of high speed SPM rotor with copper shield," 2017 IEEE International Electric Machines and Drives Conference (IEMDC), Miami, FL, 2017, pp. 1-8.

[13] G. Li, J. Ojeda, E. Hoang, M. Gabsi, and M. Lecivian, "Thermal-electroamgetic analysis for driving cyces of embedded flux-switching permanet magnet motors," in IEEE Transactions on vehicular technology, vol. 61, no. 11, pp. 140-151, 2012.

[14] M. Galea, "High perforemcne, direct drive machines for aerospace applications," $\mathrm{PhD}$ thesis.

[15] G. Li, J. Ojeda, E. Hoang, M. Gabsi, and M. Lecivian, "Thermal-electroamgetic analysis for driving cyces of embedded flux-switching permanet magnet motors," in IEEE Transactions on vehicular technology, vol. 61, no. 11, pp. 140-151, 2012 